\title{
Uma discussáo sobre a hipótese da transferência de capital no Brasil: desafios para a financeirização urbana
}

Marcos Souza. Universidade Federal do ABC, São Bernardo do Campo, Brasil.

RESUmo | A hipótese da transferência de capital, elaborada por David Harvey, conquistou grande influência nos estudos urbanos, mas sua validade empírica ainda não foi examinada no contexto brasileiro. Para discutir seus impactos realiza-se uma análise da relação entre o boom imobiliário (2007-2013) e a crise econômica (2015) enfrentada pelo país. Após uma revisão da literatura e dos estudos de caso, é analisada a especificidade brasileira no que tange à possibilidade de transferência geográfica e setorial de capital, usando dados de investimento direto estrangeiro e do investimento em máquinas e equipamentos e na construção de edifícios. Argumenta-se que as possibilidades de transferência de capital para o ambiente construído em uma economia subdesenvolvida dependem da forma específica de atuação do Estado (direta e indiretamente), das instituiçóes mediadoras e da complementariedade entre investimento público e privado.

PALAVRAS-CHAVE | crise econômica, mercado imobiliário, geografia urbana.

ABstract | The hypothesis of capital switching, elaborated by David Harvey, has achieved great status in urban studies but it has never been thoroughly applied to the Brazilian case. To test this hypothesis, we conduct an analysis of the relationship between the real estate boom (2007-2013) and the economic crisis (2015). Following a literature review, the Brazilian specificity is analyzed with regard to the possibility of geographic and sectoral capital switching, using data from foreign direct investment, investment in machinery and equipment, and investment in buildings. The role of institutional investors and the State in channeling investments into the built environment is also analyzed. It is argued that the possibilities of capital switching in an underdeveloped economy depends on the nature of State direct and indirect intervention, the role of mediating institutions and the complementarity of public and private investment.

KEYWORDS | economic crisis, real estate market, urban geography. 


\section{Introduçáo}

Uma das contribuiçóes mais longevas da economia política urbana, a hipótese ${ }^{1}$ da "transferência de capital" (capital switching), introduzida por David Harvey no artigo The urban process under capitalism: a framework for analysis (1978) foi objeto de debates e controvérsias desde então. Nos anos 1990, uma variedade de trabalhos se dedicou a investigar a validade da hipótese, usando diferentes abordagens, métodos e contextos, ainda que privilegiando países e/ou cidades do Norte Global. Surpreendentemente, embora a hipótese da transferência de capital seja um arcabouço presente em diversas discussões teóricas sobre a produção do espaço no Brasil (Valença, 2008), a literatura existente não realizou uma análise mais detalhada de sua viabilidade no contexto do país, o que demandaria também um esforço empírico de mensuração. A justificativa para tal investigação, além do desafio teórico-metodológico, se encontra no fato de que a compreensão dos movimentos de capital entre os circuitos primário e secundário tem impactos sobre o entendimento de crises econômicas e bolhas imobiliárias, sobre os processos de financeirização e as próprias formas do ambiente construído. Ainda que trabalhando em um "nível macro" de análise da economia política, pretendemos demonstrar que a hipótese da transferência de capital fornece elementos importantes para o entendimento da financeirização urbana. Embora os temas comumente abordados nessa linha de investigação tratem da financeirização via grandes projetos urbanos, da relação entre o Estado e os fundos públicos no financiamento urbano e das consequências para a reforma urbana e austeridade fiscal (Klink \& Souza, 2017), a abordagem da transferência de capital ajuda a identificar potenciais motores e barreiras para esses processos. Pretende-se argumentar que sua viabilidade em uma economia subdesenvolvida depende do papel específico que assumem o Estado e as instituiçóes mediadoras nesses contextos.

Para este trabalho, propõe-se uma análise que incorpore a evolução da economia brasileira nos anos 2000, abarcando o período compreendido como boom imobiliário (2007-2013) e a crise de 2015. Serão utilizados dados sobre investimento estrangeiro em construçóes e comparaçóes com gastos privados selecionados, além de dados sobre o fluxo financeiro direcionado para o ambiente construído.

Dessa forma, o objetivo deste trabalho é propor uma análise dos principais movimentos e entraves que sustentam a transferência de capital na economia política urbana brasileira. Assim, o artigo se encontra organizado da seguinte forma, além desta introdução: na próxima seção, será apresentada a hipótese e sua validade; a seguir, na terceira seção será discutida a contextualização do problema da transferência de capital no Brasil, com leituras sobre a transferência geográfica e setorial. $\mathrm{Na}$ quarta seção será apresentado o papel dos intermediários financeiros na transferência de capital, seguida de uma avaliação sobre a influência do contexto político na crise. Por fim, apresentaremos as conclusóes e os desafios desse tipo de abordagem.

1 Optamos por tratar a transferência de capital mais como hipótese do que teoria, devido à inexistência de sua comprovação definitiva. 


\section{A hipótese da transferência de capital}

Embora tenha surgido em artigo seminal de David Harvey (1978), a hipótese da transferência de capital acompanhou o autor em diversos trabalhos, incorporando algumas adaptaçóes. De maneira sucinta, a abordagem propóe entender a produção do espaço construído em relação com a teoria da acumulação. Assim, considera o ambiente construído como um "sistema de recursos" para a produção de valor e mais valia, analisando os processos que comandam o investimento nesse espaço e pensando em termos de produçáo e consumo. Como sintetiza Harvey, "The problem is, then, to discover how capital flows into the construction of this built environment and to establish the contradictions inherent in this process" (p. 115). Uma das bases da transferência de capital entre o circuito primário (produção de mercadorias em geral) e o secundário (produção do espaço construído) é a existência de capital e trabalho excedente, juntamente com mecanismos institucionais (sobretudo o Estado e o sistema de crédito) adequados para este direcionamento. A razão desse movimento seria predominantemente financeira, decorrente da busca por rendimentos supostamente ${ }^{2}$ mais estáveis e seguros em ativos imobiliários (ou de infraestrutura) por parte de investidores. $\mathrm{O}$ investimento no circuito secundário surge como "provavelmente a única opção que lhes resta" (Valença, 2008).

Convém lembrar que a noção de transferência de capital como possibilidade de "resolução espacial" (spatial fix) náo se resume à modalidade "setorial", do circuito primário para o secundário. Harvey também indica a transferência geográfica de capital, na qual crises de sobreacumulação em dado sistema territorial são resolvidas por meio da abertura de novos mercados e oportunidades de produção. Nesse caso, há uma necessidade de deslocamento em busca de novas oportunidades locacionais, também promovendo a desvalorização do capital (e do local) anteriormente empregado (Valença, 2008).

A hipótese da transferência de capital implica em algumas observaçóes mais diretas: 1) toda grande crise seria precedida de vultosos investimentos no ambiente construído, como uma "tentativa desesperada" de encontrar usos produtivos para o capital acumulado (Christophers, 2011). Ocorre uma queda do investimento direto produtivo, decorrente da sobreacumulação. Esta geralmente se manifesta via queda na taxa de lucros, aumento da capacidade ociosa, desemprego, e existência de capital ocioso. A transferência de capital entre os circuitos é uma "solução" apenas temporária, uma vez que os investimentos no circuito secundário passam a sofrer retornos decrescentes quando os investimentos marginais começam a esgotar a produção de mais valia e o processo é interrompido (Christophers, 2011);2) com a migração dos capitais para o ambiente construído, passa a ocorrer uma tendência de uma nova crise de valorização desses ativos; 3) a hipótese da transferência sugere a existência de alguma relação entre ciclos econômicos e ciclos imobiliários. Uma leitura mais restritiva afirma que para a transferência ocorrer, o investimento no circuito

2 Como o próprio Harvey adverte, a existência reiterada de crises e bolhas imobiliárias indica a fragilidade dessa suposição. Além disso, o investimento no circuito secundário também contém dificuldades próprias, como o longo prazo de maturação e o elevado montante de capital exigido. 
primário seria máximo na crise do circuito secundário, e vice versa, denotando sua natureza anticíclica (Beauregard, 1994); 4) surge a discussão sobre a necessidade de uma crise de sobreacumulação para a existência da transferência de capital e; 5) haveria implicitamente um privilégio no tratamento da transferência "setorial" em detrimento da transferência geográfica, pois aquela representaria melhor as leis (“necessárias") do capitalismo (Kutz, 2016).

A evolução do debate na literatura deixou patente a existência de diversas limitaçóes na hipótese da transferência de capital. Uma crítica recorrente diz respeito à concepção da dinâmica imobiliária como algo meramente derivado da dinâmica "produtiva". Nesse sentido, é irreal supor que o investimento imobiliário deve necessariamente ser consequência direta dos lucros industriais, uma vez que o setor imobiliário tem características próprias que atraem o investimento, além de uma dinâmica intrínseca e agendas e interesses específicos de seus agentes (Beauregard, 1994; Leitner, 1994). Além disso, é importante reconhecer que o capital sobrante pode náo ir necessariamente para o circuito secundário, aproveitando outras oportunidades de retorno (especulação com açóes, títulos do Tesouro, investimento externo) como afirma Beauregard (1994). O investimento em imóveis pode significar simplesmente a concessão de novos incentivos fiscais no segmento e a ausência de boas oportunidades de retorno no circuito primário, e não necessariamente uma crise de sobreacumulação (Fainstein, 1994). Em linhas gerais, o pano de fundo dessa corrente crítica é o conhecido debate sobre estrutura e agência, no qual a hipótese da transferência de capital seria acusada de funcionalista, de privilegiar movimentos deterministas ("leis") e dar pouca margem a decisóes, estratégias e contingências.

Outro conjunto de críticas questiona uma possível limitação temporal da hipótese da transferência de capital. Segundo essa visão, inovaçóes como a maior interpenetraçáo dos mercados imobiliário e financeiro que avançam nos EUA nos anos 1980, juntamente com a maior desregulamentação e a globalização do mercado imobiliário contribuiriam para tornar mais voláteis os movimentos entre os circuitos de capital, reduzindo o alcance da abordagem. Embora esse seja um aspecto relevante, conforme abordaremos adiante, não significa necessariamente uma negaçáo da hipótese da transferência, mas uma requalificação.

Como uma consequência da maior complexidade, outras críticas se dirigem às dificuldades de mensuração para comprovar ou refutar a teoria. Nesse sentido, Christophers (2011) afirma que "uma ampla e exata demonstração da transferência é impossível” devido à complexidade das interrelaçóes econômicas envolvidas, em termos de agentes, locais e tipos de interaçôes. Assim, seria irreal tentar mensurar sem ambiguidade todos os movimentos, considerando ainda que os dados que seriam necessários para tal projeto não estão disponíveis com o detalhamento exigido. Em face a essa dificuldade, diversas estratégias e variáveis são privilegiadas pelos autores em suas tentativas de analisar o fenômeno, sendo necessário ressaltar, desde já, as inevitáveis limitaçóes.

Um dos primeiros autores a tratar do problema, King (1989), ao analisar Melbourne, refuta o suposto determinismo econômico, enfatizando elementos políticos e sociais da crise, como mudanças na estrutura de classes e nas preferências da sociedade. 
Beauregard (1994) realiza análise sobre a transferência de capital nos Estados Unidos da América (EUA) no período de 1970 a 1989, não se preocupando em buscar evidências sobre a existência ou não de sobreacumulação. Seu trabalho indicou poucas evidências para validar a teoria, com poucos indícios de movimento contracíclico uma vez que o investimento privado em atividades fora da construção e na construção seguiram movimentos semelhantes, com apenas uma defasagem temporal. Em geral, o investimento produtivo e o investimento na construção caminharam juntos, e não em oposição.

A dinâmica dos ciclos imobiliários também foi investigada por Leitner (1994), ao realizar uma análise comparativa das regióes metropolitanas nos EUA entre 1963 e 1980. A autora argumenta que a transferência não é automática, sendo necessário considerar elementos como a lucratividade relativa de investimentos imobiliários com outras oportunidades de investimento, o peso das condiçôes macroeconômicas sobre o investimento imobiliário, as estratégias dos investidores institucionais e o desempenho recente do setor imobiliário.

O trabalho mais completo sobre a verificação empírica da teoria da transferência de capital foi realizado por Christophers (2011). O autor desenvolveu metodologia específica para investigar a hipótese da transferência no Reino Unido, a partir da crise do subprime de 2008. Seu objetivo foi investigar dois tipos de transferência de capital: 1) do gasto total do setor privado e 2) dos investimentos dos fundos de pensão. A metodologia, que adotaremos neste trabalho, consiste em comparar o investimento em capital fixo, que inclui vários ativos que não fazem parte do ambiente construído (máquinas, veículos, ativos intangíveis), com investimentos na construção de edifícios. O "investimento em produção", portanto, seria a combinação do gasto anual com trabalho e do gasto anual com ativos fixos "não infraestruturais" (máquinas, equipamentos, ativos intangíveis). Essa categoria é comparada com o gasto anual em construção de edifícios. Para analisar a transferência via investimento imobiliário dos investidores institucionais, o autor considera o peso particular dos fundos de pensão nessa categoria no capitalismo inglês, bem como o interesse histórico em aplicaçóes no segmento imobiliário. O objetivo é acompanhar a alocação proporcional em imóveis nas carteiras dos fundos.

Essa nova tentativa de mensuração, no entanto, não é livre de limitaçóes. Christophers (2011) reconhece que é possível ter uma noção do movimento, mas não identificar a fonte da transferência, que náo necessariamente vem do setor produtivo. Ademais, a análise dos investimentos dos fundos de pensão também contabiliza investimentos em imóveis usados e compra de títulos de imóveis que já existem. Apesar dessas restriçóes, o autor encontra evidências de um volume expressivo de transferência de capital na escalada da crise, conforme previsto pela teoria. Embora utilize análise rigorosa, o autor não considera adequadamente o impacto dos movimentos financeiros e imobiliários globais sobre a hipótese da transferência de capital no seu trabalho. A crítica é relativamente simples: se, na esteira de uma crise (que pode ser de sobreacumulação), o capital migra do circuito primário para outro país, as possibilidades de um ajuste espacial na escala nacional se dissipam.

Kutz (2016) replica parcialmente a metodologia adotada por Christophers (2011), mas insere também a dimensão geográfica ao abordar o fluxo de investimento 
direto estrangeiro. $\mathrm{O}$ autor investiga a relação entre a crise de sobreacumulação na Espanha, a bolha imobiliária (1997-2006) e o seu deslocamento geográfico para o Marrocos em busca de uma "solução" espacial.

\section{O problema da transferência do capital no Brasil}

O exercício que nos propomos realizar a seguir utiliza as consideraçóes metodológicas de Christophers (2011), adaptando-as para aspectos estruturais e conjunturais da economia brasileira. No primeiro caso, convém lembrar que economias periféricas são geralmente caracterizadas pela dependência de investimentos estrangeiros, assim como são mais vulneráveis a mudanças nos fluxos de capitais internacionais. Além disso, a profundidade da securitização e de inovaçóes financeiras atreladas a títulos imobiliários na economia brasileira é bem inferior (e mais recente) em relação aos casos apresentados. $\mathrm{O}$ mesmo se pode dizer no que tange à participação de fundos de pensão entre os investidores institucionais. Por fim, os mecanismos mediadores de que dispóe o Estado para direcionar a transferência de capital também são outros.

No que tange aos aspectos conjunturais, deve-se considerar as diferentes temporalidades das crises financeiras, produtivas e imobiliárias, bem como suas características específicas em termos de gatilhos, amplitude e duração. A seguir discutiremos com mais detalhes os condicionantes estruturais e conjunturais para a transferência de capital.

\section{A transferência geográfica via internacionalização}

Conforme já mencionado, o grau de internacionalização de atividades relacionadas ao circuito secundário pode ter impacto nas possibilidades da transferência de capital em uma economia nacional. Com o intuito de apresentar um panorama da internacionalização do mercado imobiliário no Brasil, adaptaremos algumas consideraçóes feitas por Gotham (2006), na Tabela 1.

O desafio não se limita a olhar apenas para os fluxos de investimento, mas também para as dimensóes organizacionais. Do ponto de vista das instituiçóes, isto é, do conjunto de regras que permitem uma reprodução estável do capital no tempo e espaço, é possível apontar significativo avanço no marco regulatório do mercado imobiliário no Brasil, com instrumentos notadamente inspirados no modelo americano: Fundos de Investimento Imobiliário (FII), Certificados de Recebíveis Imobiliários (CRIs), Sociedades de Propósito Específico (SPE) e alguns presentes na configuração do Sistema de Financiamento Imobiliário (SFi), criado em 1997. Somam-se a isso as mudanças regulatórias que favoreceram a oferta pública inicial de açôes (IPOss) de incorporadoras a partir de 2005.

No que tange às infraestruturas que permitem a "extensão, intensificação e velocidade das atividades e fluxos imobiliários”, o avanço é mais limitado. Apesar de algum progresso em determinadas áreas no que tange à adoção de padróes internacionais (International Valuation Standards, Red Book), ainda ocorre considerável influência da cultura local, bem como elevada variação e limitada transparência. Mesmo com importantes avanços decorrentes de pressóes de investidores internacionais e 
governos locais, ainda se configura no país um mercado de dois níveis, com as consultorias internacionais operando nas negociaçóes internacionais, enquanto as firmas locais operam com investidores locais (Royal Institution of Chartered Surveyors [RICs], 2014). A existência desse mercado híbrido não deve ser entendida como uma anomalia ou como um estágio rumo à homogeneização completa de normas, pois a adoção de lógicas e métricas de avaliação anglo-saxãs em contextos institucionais e culturais diferentes é um dos fatores que contribuem para diferentes trajetórias de financeirização (Aveline-Dubach, 2020). A mobilização da infraestrutura organizacional também tem um papel fundamental na "ancoragem" do capital financeiro. A complexidade envolvida no investimento em novos mercados implica que não se trata de um processo baseado apenas no estabelecimento de redes formais e adoção de padróes internacionais. Em muitos casos será crucial o estabelecimento de "redes territoriais transescalares" que envolvem diversos agentes, como governos locais, proprietários de terras e empresas internacionais de consultoria que fornecerão habilidades técnicas, recursos humanos e influência política para viabilizar os projetos imobiliarios e "simplificar" os mercados para investidores estrangeiros (Halbert \& Rouanet, 2014).

TABELA I | Globalização do segmento imobiliário no Brasil

\begin{tabular}{|c|c|c|}
\hline DIMENSÓES CHAVE & CONCEITUALIZAÇÃO & $\begin{array}{c}\text { MEDIDAS EMPÍRICAS E } \\
\text { INDICADORES }\end{array}$ \\
\hline \multicolumn{3}{|l|}{ Dimensóes socioeconômicas } \\
\hline \multirow[t]{2}{*}{ Extensão } & $\begin{array}{l}\text { Alargamento das atividades } \\
\text { imobiliárias e de construção entre } \\
\text { fronteiras }\end{array}$ & $\begin{array}{l}\text { Grau de IDP em atividades imobi- } \\
\text { liárias e construçáo }\end{array}$ \\
\hline & & $\begin{array}{l}\text { Grau de IDE em atividades imobi- } \\
\text { liárias e construçấo }\end{array}$ \\
\hline \multicolumn{3}{|l|}{ Dimensốes organizacionais } \\
\hline \multirow[t]{2}{*}{ a) Infraestruturas } & Normas, procedimentos e redes & $\begin{array}{l}\text { Desenvolvimento de padróes } \\
\text { internacionais, mecanismos } \\
\text { financeiros e leis de licenciamento }\end{array}$ \\
\hline & & $\begin{array}{l}\text { Crescimento de redes internacio- } \\
\text { nais de atividades imobiliárias e } \\
\text { construçấo }\end{array}$ \\
\hline b) Instituições & $\begin{array}{l}\text { Regras de trocas, estruturas de go- } \\
\text { vernança, direitos de propriedade } \\
\text { e concepçóes de controle }\end{array}$ & $\begin{array}{l}\text { SFI, alienação fiduciária, SPE, IPOS, } \\
\text { CRIS, FII }\end{array}$ \\
\hline
\end{tabular}

NOTA: IDP: INVESTIMENTO DIRETO NO PAÍS; IDE: INVESTIMENTO DIRETO NO EXTERIOR; SFI: SISTEMA DE FINANCIAMENTO IMOBILIÁRIO; SPE: SOCIEDADES DE PROPÓSITO ESPECÍFICO; IPO: INITIAL PUBLIC OFFERING / OFERTA PÚBLICA INICIAL DE AÇÓES; CRI: CERTIFICADOS DE RECEBÍVEIS IMOBILIÁRIOS; FII: FUNDOS DE INVESTIMENTO IMOBILIÁRIO

FONTE: ELABORAÇÃO PRÓPRIA ADAPTADA DE GOTHAM (2006)

Observando as dimensôes socioeconômicas da globalização do segmento imobiliário, encontra-se uma extensão reduzida. Os gráficos a seguir representam a participação da contrução e das atividades imobiliárias no investimento direto no país (IDP) e no investimento direto no exterior (IDE), segundo o critério participação do 
capital. ${ }^{3}$ Com a finalidade de tentar mensurar os fluxos de capital para o ambiente construído, analisaremos dados sobre a construção (a partir de 2006 desagregados em construção de edifícios e obras de infraestrutura) e sobre atividades imobiliárias. Embora a construção de edifícios seja o indicador mais comumente associado à hipótese da transferência de capital (Christophers, 2011) incluímos nessa seção as atividades imobiliárias, por incorporarem a gestão de propriedade imobiliária e a administração de diversos tipos de imóveis (como condomínios e shopping centers), atividades que foram alvo de significativos investimentos estrangeiros.

\section{FIGURA I | Investimento direto no país (\%)}

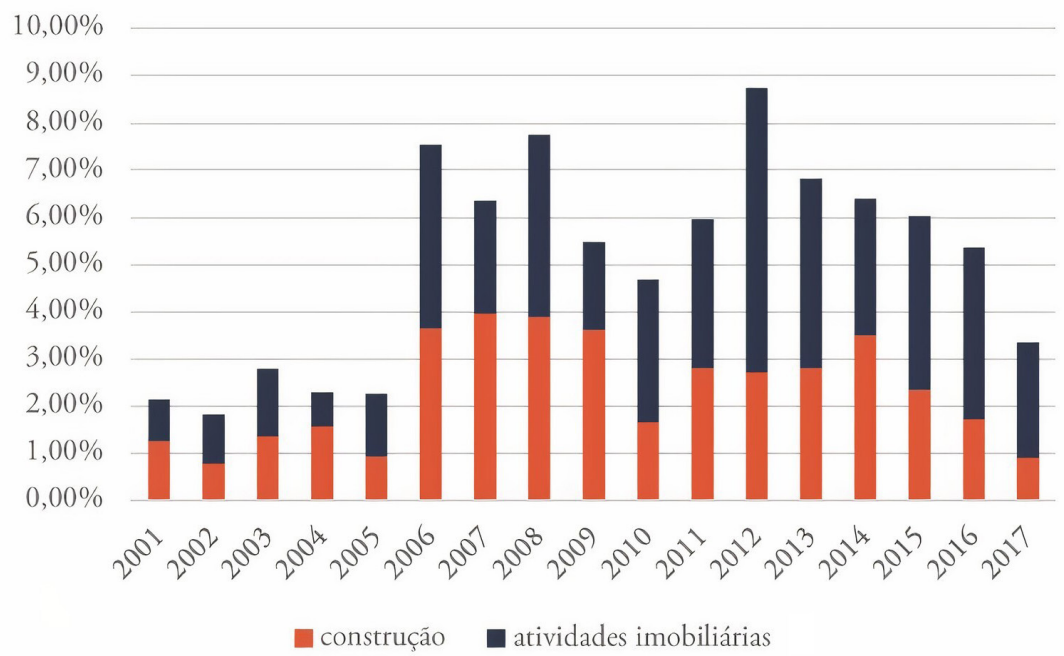

FONTE: BANCO CENTRAL DO BRASIL

Se considerarmos os dados sobre construção, disponíveis desde 2001 (Figura 1), fica nítido o maior investimento de estrangeiros no país (IDP) nos anos 2006-2009 e em 2014 (nesse ano, liderado pelos gastos em obras de infraestrutura). Ao utilizarmos os dados desagregados (Figura 2), constata-se que a construçáo de edifícios foi a principal responsável pelo desempenho no período, alcançando percentual acima de 2,5\% do total de IDP nos 3 primeiros anos, e máximo em 2007 (3,61\%). A queda na participação da construção de edifícios a partir de 2009 passa a ser compensada pelo aumento na participação das obras de infraestrutura no IDP. Esta alcança patamares similares e até maiores à construção de edifícios em 2014 (2,03\%) e 2015 (1,19\%). A origem dos investimentos, com larga margem, vem dos EUA, mas sem

O Banco Central do Brasil considera relação de investimento direto quando um investidor de uma economia detém poder de voto igual ou superior a $10 \%$ em empresa de outra economia. Já o componente Participação no Capital diz respeito, no caso de passivos, ao investimento de náo residentes alocado no capital de empresas residentes no Brasil e, no caso de ativos, ao investimento de residentes no Brasil alocado no capital de empresas residentes no exterior (Banco Central do Brasil [вСв], 2018). As séries disponíveis são mais completas para o IDP, pois permitem analisar o ingresso de capitais (fluxo) e por um período maior. Para análise do IDE será utilizada a posição de capital. 
nunca atingir 0,9\% do total de IDP (dados por países disponíveis a partir de 2010). Considerando as atividades imobiliárias destaca-se a maior presença no IDP a partir de 2006. Em que pese a queda em 2009 (1,87\%), a participação das atividades imobiliárias no total do IDp se manteve no período geralmente acima de 3\%, com destaque para o ano de 2012 (6,03\%). Os EUA também se destacam sendo o único país com participação das atividades imobiliárias no IDP maior do que 1\%. Essa participação se manteve acima deste nível em todo o período, ultrapassando o patamar de 2\% em 2012 (2,01\%), 2013 (2,56\%), 2015 (2,08\%) e 2016 (2,77\%). Apesar da participação bem maior que outros países, se compararmos o fluxo de investimentos da construção e atividades imobiliárias (máximo de 5,2 US\$ bilhóes em 2012) com о РIв da construção dos EUA no período (variou entre 500 e 800 US\$ bilhóes), não faz sentido afirmar que o ambiente construído brasileiro representa a solução espacial para crises no circuito primário americano.

FIGURA 2 Investimento direto no país (\%) - desagregado

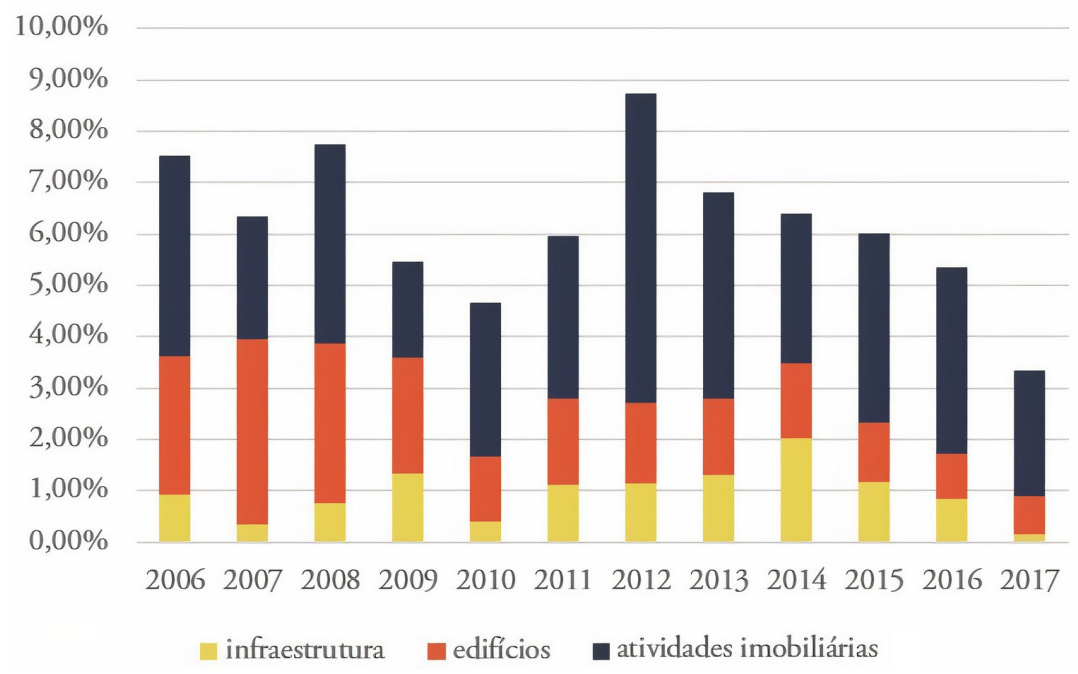

FONTE: BANCO CENTRAL DO BRASIL

Em relação à possibilidade de a crise no circuito primário ser exportada para outro país, recorre-se à análise do investimento direto no exterior (Figura 3).

Ao decompor esse setor (dados desagregados a partir de 2007), observa-se que a construção de edifícios no exterior é praticamente irrelevante. $\mathrm{O}$ setor é dominado por obras de infraestrutura na esteira da internacionalização das grandes empreiteiras, processo que começou em fins dos anos 1960 e compreendeu variados estágios. No ciclo mais recente (a partir de 2003), marcado pela intensificação da internacionalização de empreiteiras e seu papel na política de "campeâs nacionais", os principais países receptores são Angola (2012 a 2014) e Venezuela (2015 a 2017), caracterizados por má posição em rankings globais de corrupção (Gonçalves, 2017). Como outros receptores, em patamar bem inferior, cabe mencionar também Peru, 
Portugal e, mais recentemente, Espanha. A participação das obras de infraestrutura no IDE atinge novo patamar a partir de 2012, sendo que mesmo no auge para um determinado país (Venezuela em 2015, com posição de capital de US\$ 1,9 bilhão) esta atingiu apenas 2,2\% do РIB da Construção no Brasil no ano. Com efeito, apesar da concentração em cinco grandes empreiteiras nacionais, o mercado internacional é relativamente pouco importante para essas empresas em termos de faturamento. Esses dados também permitem afastar a hipótese da transferência de capital no circuito primário do Brasil para um determinado país mesmo considerando a Construção (edifícios + obras de infraestrutura) como circuito secundário.

Observando as atividades imobiliárias, chama a atenção o crescimento destas em 2007 com sua relativa estabilizaçáo entre 2,2\% e 2,8\% do total do IDE a partir de 2009. Mais uma vez, o principal destino é destacadamente os EUA, com a participação crescente a partir de 2011 e ultrapassando o patamar de $2 \%$ em relação ao PIB das atividades imobiliárias em 2015 e 2017.

\section{FIGURA 3 | Investimento direto no exterior (\%) - desagregado}

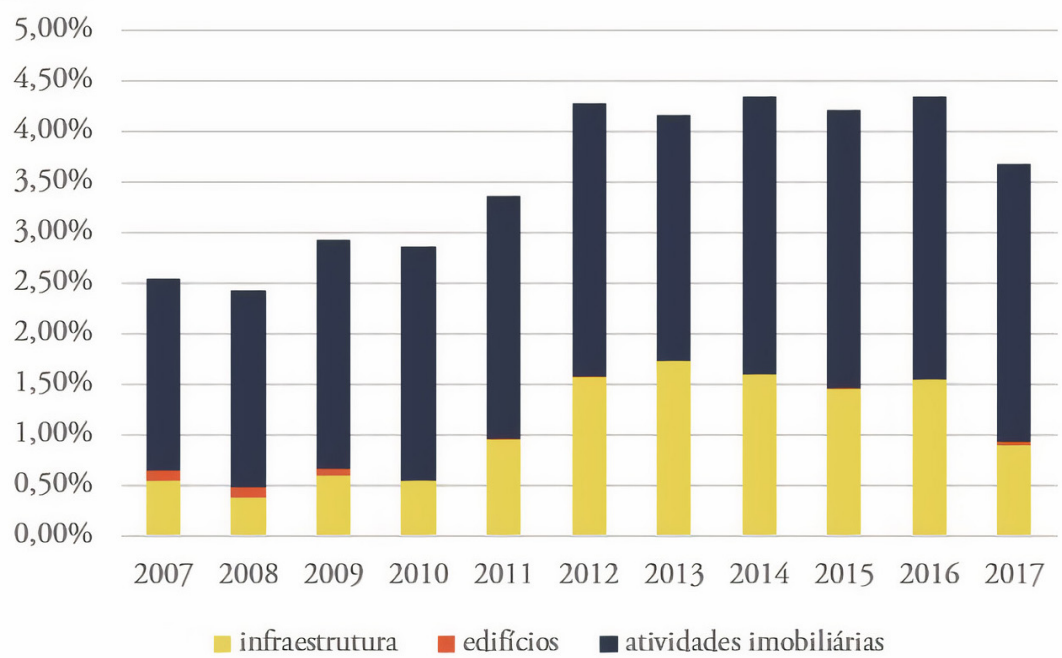

FONTE: BANCO CENTRAL DO BRASIL

Afastada também a possibilidade de uma transferência geográfica de capital para outro país, ${ }^{4}$ é necessário aprofundar a discussão acerca da ocorrência de uma transferência setorial. 


\section{Dinâmica de investimento e a transferência setorial}

Em que pese não haver consenso sobre a causa do sucesso, é reconhecido que na primeira década dos anos 2000 a economia brasileira passou por um processo de crescimento peculiar, com novas contradiçóes. Para fins de simplificação, adotaremos aqui a periodização proposta por Carvalho (2018). Segundo a autora, nos primeiros anos do Governo Lula (2003-2005) a principal novidade consistiu nos programas de transferência de renda, num contexto de forte ajuste fiscal e crescimento liderado pelas exportaçóes de commodities. Já o período entre 2006-2010 é tratado como "Milagrinho", marcado por aumento real de salários, elevação do emprego formal, redução nas desigualdades de renda, melhora nas contas públicas e forte crescimento do investimento $(9,1 \%$ ao ano no período, enquanto o investimento federal cresceu 27,6\%). Sua sustentação estava baseada em três pilares: distribuição de renda, aumento do crédito e investimentos em infraestrutura. Destaca-se o investimento público na esteira do Programa de Aceleração do Crescimento (PAC, $2007)$ priorizando investimentos em energia, infraestrutura social e urbana $(33,9 \%$ do total) e logística.

A crise financeira internacional de 2008 afetou a exportação de commodities num primeiro momento, mas após dois trimestres a economia voltou a crescer, em virtude das políticas anteriores e de medidas emergenciais. Uma medida mais permanente se destacou, no entanto: a criação do Programa Minha Casa Minha Vida ( da quebra decorrente da venda de açóes por investidores após a crise do subprime; funcionar como política contracíclica diante do cenário desfavorável e atuar politicamente junto ao segmento de mais baixa renda (Rolnik, 2015).

Houve uma reversão do cenário em 2011, já no governo Dilma Rousseff (20112016). Além da piora no quadro internacional, o período marca o fim da expansão dos investimentos públicos em infraestrutura, que foram substituídos por políticas de desonerações tributárias, concessóes e outros estímulos ao setor privado em um movimento de aproximação com as demandas do empresariado, resumida por Carvalho (2018) como a "Agenda Fiesp", em referência à Federação das Indústrias do Estado de São Paulo. No entanto, diversos problemas como a administração da agenda microeconômica, preferência pelo investimento privado e pressóes inflacionárias fizeram com que o investimento público tenha sido a variável de ajuste, num contexto de corte do PAC (2015) e impactos da Operaçáo Lava Jato sobre a construção civil (2015).

Em parte do período em tela, ocorreu um intervalo marcado por elevação dos preços e da produção imobiliária no país (2007-2013), trazendo à tona a hipótese de existência de uma bolha. Esse período é delimitado pelo excepcional aumento de lançamentos residenciais na cidade de Sáo Paulo, na esteira da abertura de capital das incorporadoras, e pela trajetória de queda a partir de 2013, após ajuste da produção em 2012 (sEcovi, 2016). O boom foi provocado por diversos fatores, como a maior liquidez decorrente da abertura de capital de incorporadoras, melhoria das condiçôes de financiamento, direcionamento de recursos da poupança para o crédito imobiliário, novo marco regulatório para o setor, criação do PMCMV e melhoria do cenário macroeconômico (Rolnik, 2015). Essas transformaçôes marcam também 
a ruptura com o padrão de urbanização anterior, diante da expansão territorial das grandes incorporadoras baseadas na região sudeste, a corrida pela formação de bancos de terra e o estabelecimento de parcerias com construtoras em outras regiōes (Sanfelici, 2013). A realização de parcerias com atores locais possibilitou diversificação de estratégias (geográficas e em direção ao segmento de menor renda) e um volume muito maior de investimentos, mas também foi fonte de conflitos decorrente do choque de cultura de gestão e perda de poder das empresas locais (Rufino, 2016). Outra fragilidade do período de boom foi a adoção de narrativas e métricas de crescimento pela comunidade de incorporadores, analistas financeiros e gerentes de fundos que, posteriormente, se mostraram equivocadas (Sanfelici \& Halbert, 2016).

Para investigar a hipótese da transferência setorial de capital do circuito primário para o secundário é necessário, primeiramente, analisar a evolução do investimento na produção e na construção de edifícios, seguindo a metodologia proposta por Christophers (2011).

\section{FIGURA 4 | Construções de edifícios/gastos privados totais}

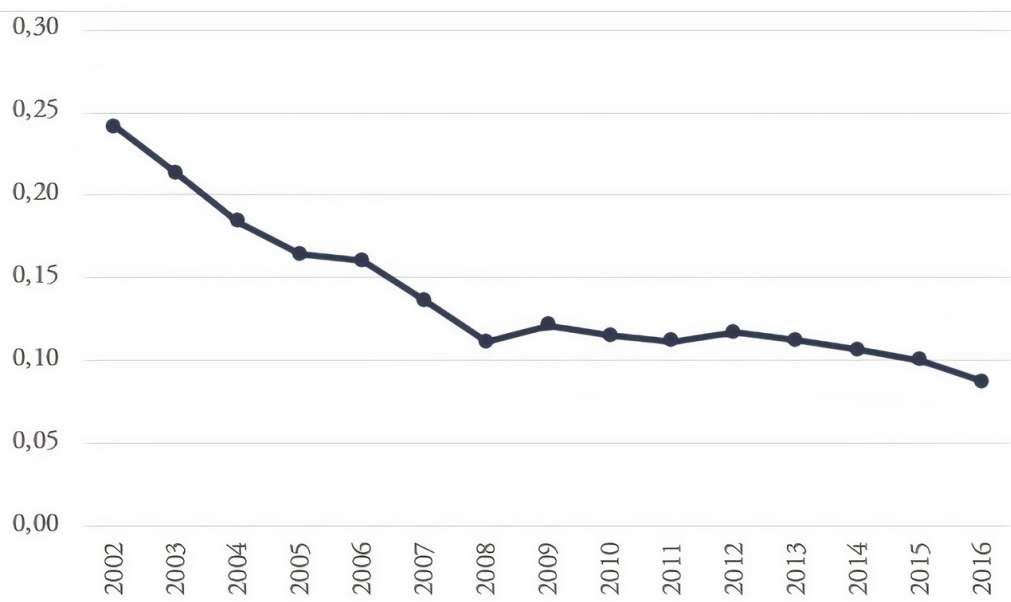

FONTE: ELABORAÇÃO PRÓPRIA A PARTIR DE INSTITUTO BRASILEIRO DE GEOGRAFIA E ESTATÍSTICA (IBGE) (20I7, 2OI 8), INSTITUIÇÁO FISCAL INDEPENDENTE (IFI) (2OI7) E IPEADATA (2O2O). ANO BASE 20I6, DEFLACIONADO PELO ÍNDICE NACIONAL DE PREÇOS AO CONSUMIDOR AMPLO (IPCA)

Os dados da Figura 4 indicam uma significativa queda na construção de edifícios em relação ao gasto privado total inicial (de $24,1 \%$ em 2002) e uma participação relativamente estável, de pouco acima de $11 \%$ nos anos do boom imobiliário 
(2007-2013), após um pico em 2007 (13,6\%). ${ }^{5}$ Esses resultados, em uma primeira observação, contradizem a hipótese da transferência de capital, uma vez que era de se esperar a migração dos investimentos para a construção de edifícios nos anos que precedem a crise econômica (2015), como "tentativa desesperada", produzindo um boom imobiliário como verificou-se na Inglaterra no período 2000-2007. No Brasil houve apenas uma mudança na trajetória de queda, com o boom imobiliário sustentando a participação da construção de edifícios nos gastos privados totais. Os resultados (Figura 5) podem parecer contraditórios considerando os incentivos para investimento imobiliário já mencionados, mas a análise comparada da taxa de crescimento anual composta (Compound Annual Growth Rate, CAGR, por sua sigla em inglês) de despesas selecionadas fornece informaçóes relevantes (Tabela 2).

\section{FIGURA 5 | Gastos privados selecionados (em R\$ milhôes)}

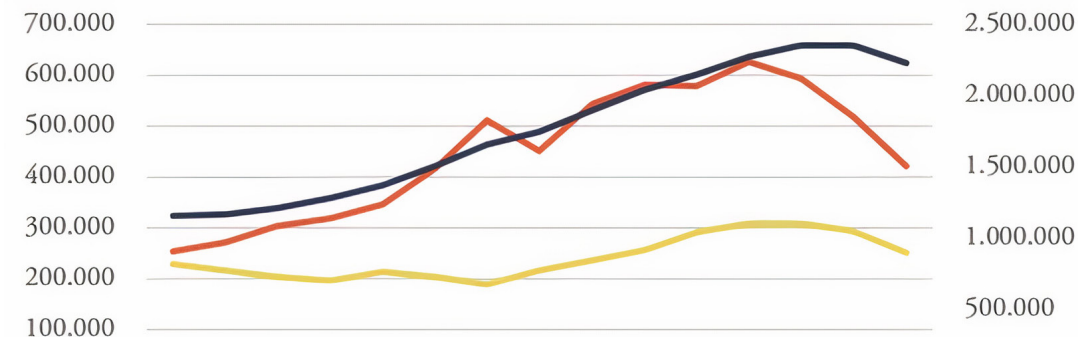

100.000 500.000

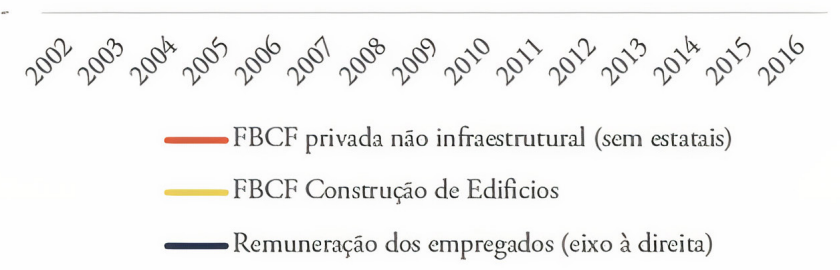

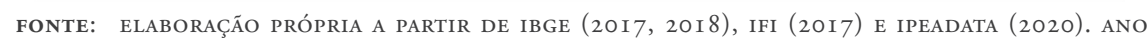
BASE 2OI6, DEFLACIONADO PELO IPCA

Embora de fato ocorra uma diminuição da CAGR da formação bruta de capital fixo $(\mathrm{FBCF})$ "não infraestrutural" nos anos do boom imobiliário em relação ao período anterior, ainda assim essa taxa é bastante próxima da taxa de crescimento da FBCF de construçóes residenciais. Se considerarmos ainda a CAGR da remuneração dos empregados, não há diferenças significativas entre o "investimento na produção" privado e o investimento privado em construçóes de moradias. Comparando o período pré boom e o boom, ocorreu uma situação na qual houve queda da $\mathrm{FBCF}$ não

5 O tratamento dos dados demanda determinados procedimentos metodológicos. A série de Formação Bruta de Capital Fixo na construção (sCN/IBGE) só apresenta a desagregação em construçôes residenciais a partir de 2010. Para estabelecer os valores entre 2002 e 2010 recorreuse a estimaçôes com base na série de valor adicionado na construção de edifícios da Pesquisa Anual da Indústria da Construção (IBGE), onde verificou-se a correlação de $92 \%$ entre as duas séries. Nesse caso, deve-se ainda reconhecer que a construção residencial não responde por toda a construção de edifícios e que parte desta se encontra em “outros edifícios e estruturas" (sCN/IBGE). 
infraestrutural, aumento da FBCF na construção residencial (como prevê a hipótese), mas quase equivalência das variáveis durante o boom imobiliário. A questão crucial, então, foi a manutenção de elevado nível de investimento na produção, considerando também a elevação do emprego e valorização salarial, que não migrou para o investimento em construção durante o boom.

TABELA 2 | Gastos selecionados

\begin{tabular}{|c|c|c|c|c|c|}
\hline \multirow{2}{*}{ PERÍODO } & \multicolumn{4}{|c|}{ GASTOS PRIVADOS } & $\begin{array}{c}\text { GASTOS } \\
\text { PÚBLICOS }\end{array}$ \\
\cline { 2 - 6 } & $\begin{array}{c}\text { FBCF } \\
\text { CONSTRUÇÓES } \\
\text { RESIDENCIAIS }\end{array}$ & $\begin{array}{c}\text { FBCF } \\
\text { CONSTRUÇÓES }\end{array}$ & $\begin{array}{c}\text { FBCF não } \\
\text { INFRAESTRU- } \\
\text { TURAL }\end{array}$ & $\begin{array}{c}\text { REMUNERAÇÃo } \\
\text { SALÁRIOS }\end{array}$ & $\begin{array}{c}\text { FBCF ADM. } \\
\text { PÚBLICA }\end{array}$ \\
\hline $2002-2007$ & $-2,4 \%$ & $-2,2 \%$ & $10,2 \%$ & $5,4 \%$ & $2,1 \%$ \\
\hline $2007-2013$ & $7,2 \%$ & $6,6 \%$ & $7,1 \%$ & $7,1 \%$ & $12,5 \%$ \\
\hline $2002-2016$ & $0,7 \%$ & $0,6 \%$ & $3,6 \%$ & $4,8 \%$ & $1,3 \%$ \\
\hline
\end{tabular}

FONTE: ELABORAÇÃo PRÓPRIA A PARTIR DE IbGe (20I7, 20I8), IFI (20I7) E IPEAdATA (2020). ANO BASE 2016

Os resultados divergem de forma consistente daqueles verificados por Christophers (2011) para Inglaterra e Estados Unidos, onde o crescimento do investimento em moradias no período de boom imobiliário analisado pelo autor nos dois países foi em torno de 4,5\%-5\% contra um crescimento próximo de $1,5 \%$ em salários e negativo para o componente náo infraestrutural. Verifica-se no Brasil uma lógica particular na dinâmica do investimento, que implica em restriçóes para a hipótese da transferência de capital. Se essa hipótese está baseada em alguma medida no grau de decisão dos empresários, faz sentido considerar preferencialmente os gastos privados, como faz Christophers. No entanto, no caso brasileiro e no período assinalado, destaca-se a importância do investimento da administração pública e empresas estatais, tanto nas construçóes quanto no investimento não infraestrutural. Ademais, investimentos em máquinas e equipamentos e investimentos em construções têm dinâmicas estruturalmente distintas. Enquanto empresas não financeiras são as principais responsáveis pelos investimentos em máquinas e equipamentos (34\% em 2000 e $27 \%$ em 2009), as famílias ( $46 \%$ em 2000 e $47 \%$ em 2009) e o governo (19\% em 2000 e $27 \%$ em 2009) são mais responsáveis pelo investimento em construçóes (Santos et al., 2016). Assim, a aceleração do investimento público em construçóes se deu na esteira do PAC (2007-2014) e do PMCMV (2009), sendo a fase inicial do primeiro programa sustentada em investimentos e financiamento público, enquanto a partir de 2010 tentou-se atrair o investimento privado. É interessante observar que a taxa de crescimento anual composta da construção de edifícios foi maior que a da construção em geral no período 2007-2013. Ainda assim, se analisarmos o período completo (2002-2016), fica claro que a série de FBCF em máquinas e equipamentos cresce mais e é mais reativa ao ciclo econômico que a $\mathrm{FBCF}$ em construçóes, sendo essa mais estável devido ao maior peso das famílias e governo (Santos et al., 2016). Esse dado reduz as possibilidades de transferência de capital para o circuito secundário com base nas decisóes e gastos 
privados dos agentes empresariais, de modo que o papel anticíclico das construçóes de edifícios depende necessariamente da atuação do Estado (direta e indiretamente, via financiamento) e da complementariedade entre investimento público e privado. A fBCF da Administração Pública foi o componente que mais cresceu no período de 2007-2013 (CAGR de 12,5\%), tendo um papel importante na dinâmica do investimento na produção e na construção e alcançando o auge em 2010, para sofrer forte queda a partir de 2014 .

\section{Os intermediários financeiros}

Para compreender a dinâmica da mobilização de recursos que sustentaram a produção imobiliária no período é necessário também analisar a natureza dos fluxos financeiros. Os fundos de previdência, juntamente com as seguradoras e os fundos mútuos, configuram os chamados investidores institucionais. Em 2014, no Brasil, os fundos mútuos de investimento eram responsáveis por $55 \%$ da carteira consolidada dos investidores institucionais, enquanto as Entidades Fechadas de Previdência Complementar (EFPC) respondiam por $24 \%$ e as Entidades Abertas de Previdência Complementar (EAPC) por 15\% (Oliveira et al., 2017). As EFPC, comumente associadas aos fundos de pensão, são ligadas a entidades patrocinadoras e coletam recursos dos trabalhadores com vínculos com a empresa ao longo de seu tempo de trabalho, enquanto as segundas são planos contratados por pessoas físicas junto a bancos ou seguradoras (Oliveira et al., 2017). Devido a maior acessibilidade de dados, será privilegiada nesse trabalho a análise das EFPC. Outra distinção importante é entre os planos de benefícios definidos (BD) e os de contribuiçáo definida (CD). Existe uma tendência global de migração para os planos $\mathrm{CD}$, que operam com compromissos mais baixos já que o montante a ser recebido varia em função da rentabilidade do fundo. O resultado é um menor incentivo ao investimento em aplicaçôes fora da segurança e liquidez da renda fixa. Por outro lado, estudos apontam para o forte crescimento recente de ativos das EAPC no Brasil, o que pode significar nova tendência na alocação dos recursos. Os participantes em planos destas entidades não têm compromisso com aplicaçóes de longo prazo, portanto elas tendem a adotar estratégias curto-prazistas de gestão de carteiras, migrando para atividades mais promissoras no momento.

A configuração dos investidores institucionais no Brasil tem uma relevância no potencial dos mesmos como direcionadores da transferência de capital para investimentos no ambiente construído. Apesar da pouca liquidez dos imóveis e da baixa profundidade dos mercados secundários para títulos atrelados a esses ativos, seu desempenho recente permite reflexôes importantes.

Para a discussão do investimento imobiliário dos fundos de pensão consideramos o investimento direto (propriedade do imóvel), indireto (propriedade de ativos financeiros atrelados a imóveis) e financiamento imobiliário. Enquanto o período de 2002-2007 configura um crescimento da carteira das EFPC, a participação de imóveis nos fundos de pensão (eixo à direita na Figura 6) diminui, tornando nítida a preferência por outros investimentos por parte destes investidores institucionais, com destaque para crescimento da renda variável. A partir de 2007, os imóveis 
se tornam uma opção mais atrativa, apresentando um crescimento consistente ao longo do boom imobiliário, com a participação chegando a 5,1\% do total em 2013, e mantendo-se em níveis semelhantes (5,3\% em 2014 e 2015) antes de recuar. A taxa de crescimento anual dos investimentos imobiliários (eixo à esquerda da Figura 6) atinge maiores valores nos anos 2010, 2011 e 2012.

\section{FIGURA 6 | Investimento em imóveis: fundos de pensão e fundos de investimento imobiliário}

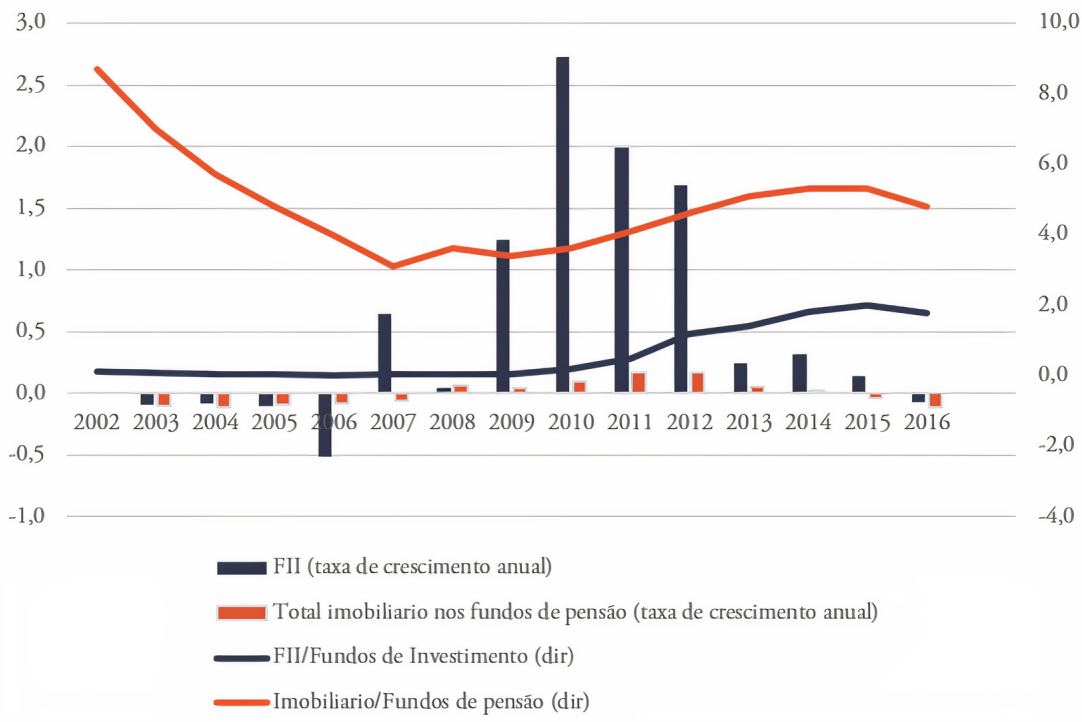

FONTE: ELABORAÇÃO PRÓPRIA A PARTIR DE ASSOCIAÇÃo BRASILEIRA DAS ENTIDADES DOS MERCADOS FINANCEIROS E DE CAPITAIS (ANBIMA) (20I9) E ASSOCIAÇÃO BRASILEIRA DAS ENTIDADES FECHADAS DE PREVIDÊNCIA COMPLEMENTAR (ABRAPP) (2OI9). ANO BASE 2OI6, DEFLACIONADO PELO IPCA

Considerando o patrimônio líquido dos fundos de investimento imobiliário, observa-se que após o impacto da crise de 2008 o segmento apresentou elevadas taxas de crescimento anual entre 2009 e 2012 (124\%, 273\%, 199\% e 168\%, respectivamente). No entanto, embora a participaçáo dos FIIs no patrimônio líquido total dos fundos de investimento tenha comportamento muito semelhante à participação dos investimentos imobiliários dos fundos de pensão, cabe notar que o peso relativo é bem menor, só ultrapassando o patamar de 1\% a partir de 2012 .

Para avaliar o papel do fluxo de investimentos no ambiente construído via sistema financeiro, é fundamental considerar os repasses do Sistema de Financiamento Habitacional (SFH), que administra recursos do Fundo de Garantia por Tempo de Serviço (FGTS), oriundos de contribuição trabalhista, e do Sistema Brasileiro de Poupança e Empréstimo (sBPE), oriundos do sistema bancário. Os dados absolutos (Figura 7), reafirmam a diferente ordem de grandeza dos recursos do SFH (eixo à direita no gráfico). O gráfico demonstra que a transferência de recursos via SFH foi anterior aos demais mecanismos, devido à série de medidas adotadas no início dos anos 2000 (mudanças nas regras de cômputo da exigibilidade para 
crédito habitacional, melhor gestão do FGTS, no Ministério das Cidades, primeiro ciclo de abertura de capital entre 2005 e 2007 e melhoria do cenário macroeconômico). Nos anos do boom imobiliário (2007-2013), a taxa de crescimento anual composta (CAGR) do FGTS (27\%) e do SBPE (28\%) foi quase idêntica, indicando uma convergência no uso do fundo público e crédito direcionado para o financiamento imobiliário. Não obstante, o direcionamento dos recursos do SBPE no período voltou-se principalmente para aquisição de imóveis (CAGR de 36\%, contra CAGR de $17 \%$ da construção), o que diminui o peso desse mecanismo na transferência de capital. Em relação ao FGTs, cabe lembrar seu papel como "colchão de liquidez", através de aportes anuais para compra de CRIs ou cotas de FIIs garantindo uma liquidez mínima para esses mercados. Segundo Royer (2016, p. 46), o fundo acaba se comportando de forma semelhante a um investidor institucional, preocupado com a valorização dos títulos e sendo decisivo na alocação de recursos, na escolha do tipo de investimento e sua localização.

\section{FIGURA 7 | Fluxos de investimentos em imóveis}

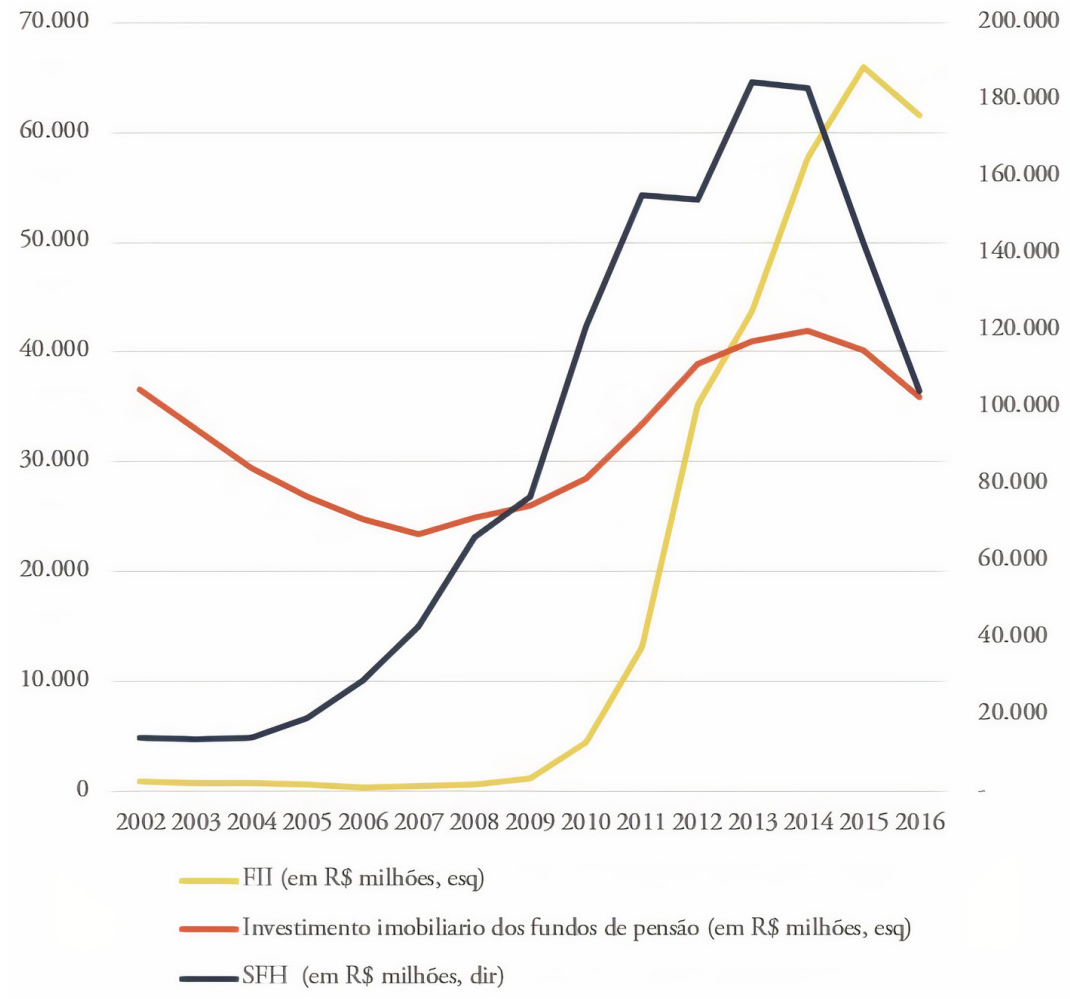

FONTE: ELABORAÇÃo PRÓPRIA A PARTIR DE ANBIMA (2OI9), ABRAPP (2OI9) E UQBAR (2OI7). ANO BASE 2OI6, DEFLACIONADO PELO IPCA 
Os dados apresentados permitem as seguintes observaçóes:

1. Todas as séries indicam aumento do fluxo de investimentos imobiliários no período 2007-2013, em linha com a hipótese da transferência de capital. O ano de pico variou: 2014 (fundos de pensão e SFH) e 2015 (FIIs). A não coincidência exata com 2013 pode estar relacionada à menor liquidez dos imóveis, dificultando as vendas na crise, bem como manutenção de preços de imóveis em algumas cidades até 2014 .

2. O Cagr dos fluxos imobiliários no período do boom foi maior nos fiIs (110\%), seguido do SFH (27\%) e dos fundos de pensão (10\%). A participação dos FIIs no total dos fundos de investimentos se manteve relativamente baixa devido ao elevado crescimento da indústria de fundos em geral, com diversidade de opçóes (cambiais, curto prazo, renda fixa, açôes, multimercado, etc.).

3. Os recursos do SFH são significativamente mais volumosos e mais pró cíclicos, devido às características de seu funding, e sofreram mais com a reversão da economia em 2014. Esse mecanismo é fundamental para explicar a hipótese da transferência de capital no Brasil, e cabe lembrar que a parcela do sistema bancário destinou mais recursos à aquisição de imóveis do que à construção no período.

4. Os fundos de pensão apresentaram menores níveis de pico e de oscilação, confirmando sua característica conservadora e o fato de que imóveis ainda são considerados "ativos alternativos". As transformaçôes na indústria de fundos de pensão apontam para o crescimento das entidades abertas, que são mais curtoprazistas, e dos planos de contribuição definida ou variável, que buscam opçóes mais seguras. O papel desses agentes como canais para a transferência de capital dependerá do aumento da liquidez e da ampliação do mercado secundário de opçóes como os FIIs, além de menores incentivos para aplicaçóes em renda fixa.

5. A mobilização de uma parte da poupança para o circuito secundário foi caracterizada no período analisado. No entanto, essa mobilização não se deu em detrimento do "investimento na produção", que também teve desempenho de alta no período. Dessa forma, não se pode afirmar que os recursos foram transferidos do circuito primário. Essa coincidência na FBCF implica que a transferência de capital no Brasil e seus eventuais bloqueios náo podem ser explicados por elementos puramente econômicos.

\section{O componente político}

Conforme discutido, a hipótese da transferência de capital já foi criticada por seu possível viés economicista, ao implicar que o movimento de saída do circuito primário ocorre por esgotamento de oportunidades lucrativas. Como demonstrado, isso náo ocorreu no Brasil. Por outro lado, a crise vivenciada no país não poderia ser reduzida a uma crise de transferência de capital. Com efeito, é preciso entender o processo sob a lógica do deslocamento de crises econômicas para o sistema político. King (1989) propóe uma complementação entre a noção de crise econômica desenvolvida por 
Harvey e a de crise política abordada por Habermas, que é útil para entender o caso brasileiro e o processo mais geral de transformação social. Nesse contexto, a crise da transferência de capital coincidiu com a crise do desenvolvimentismo e o que Fraser (2018) denomina como "contradiçôes políticas do capitalismo financeirizado".

Como visto, a resposta à crise de 2008 através de uma série de programas públicos (PAC, PSI, PIL, PMCMV), desoneraçôes e atuação dos bancos públicos manteve o investimento na produção e o investimento em construçôes em níveis elevados. Essas medidas foram reflexo de um viés desenvolvimentista nos governos a partir de 2002 e que, apesar de ser contido em 2013, vinha passando por conflitos internos desde 2011 (Singer, 2015). Chama a atenção as disputas entre as fraçôes industrialistas e rentista e a posterior coalizão de ambas contra o governo, o que inviabilizou a própria "Agenda FIESP (Federação das Indústrias do Estado de São Paulo)" e o esforço de redução da taxa básica de juros, iniciado em 2011. A crise assume outra dimensáo com os protestos de rua em junho de 2013 e a Operação Lava Jato, em 2015. A inclusão da dimensão política permite afirmar que não se verificou uma crise de transferência tradicional, no sentido de uma fuga massiva dos investimentos produtivos para o setor imobiliário ou de eventual bloqueio a esse movimento, mas uma crise administrativa, no sentido de Habermas, na qual o poder público perde a capacidade de governar efetivamente, ou de tomar as decisóes racionais adequadas (King, 1989; Fraser, 2018). A crise enfrentada no sistema político envolve elementos da dificuldade de administração de distorçôes do modelo desenvolvimentista (déficit de participação popular, desigualdades socioespaciais, oferta precária de serviços públicos nas grandes cidades) agravadas pelas novas contradiçóes políticas do capitalismo financeirizado (colonização do poder público pelas finanças, ascensão das PpPs que privilegiam consumidores e não cidadãos, e emergência de novas subjetividades neoliberais). Embora a superação dessa crise administrativa via uma crise de legitimação do capitalismo financeiro ainda não se encontre no horizonte, o risco de "desdemocratização" já é uma realidade (Fraser, 2018). A crise econômica no Brasil não seguiu o roteiro transferência de capital/ crise imobiliária/crise econômica. $\mathrm{O}$ que vimos foi uma convergência entre as crises econômica e política -esta com um forte componente urbano-, numa crise administrativa que contaminou o segmento imobiliário, embora este tivesse suas contradiçôes internas.

\section{Conclusáo}

Com o intuito de interpretar a hipótese da transferência de capital no contexto urbano brasileiro procurou-se, primeiramente, considerar possíveis limitaçóes desse arcabouço diante da globalização da construção e das atividades imobiliárias. $\mathrm{O}$ objetivo desta análise parcial foi identificar se ocorreria o deslocamento em busca de uma soluçáo espacial via investimento direto para o exterior ou para o país. A pouca extensão socioeconômica e organizacional dessas atividades confirma que não ocorreu esse movimento de transferência geográfica, devendo a análise voltar-se para a possibilidade de transferência setorial. 
Os dados analisados permitem concluir que não há evidências que suportem a hipótese da transferência de capital no contexto brasileiro no período estudado, de 2002 a 2016. Apesar da redução do investimento em máquinas e equipamentos acompanhada de aumento do investimento na construção de edifícios ao longo do boom imobiliário no Brasil (medido pelo CAGR), os níveis de investimento na produção continuaram elevados, com aumento do gasto com remuneração salarial e sem sinais de esgotamento, ao contrário do que implica a hipótese da transferência. No entanto, houve um direcionamento consistente de recursos financeiros de investidores institucionais e do SFH para o ambiente construído no período.

Essas constataçôes implicam que não se verifica o caráter anticíclico esperado em interpretaçóes sobre a transferência de capital (Beauregard, 1994). No Brasil, o investimento imobiliário ocorreu concomitantemente com o investimento no setor produtivo da economia. O presente artigo argumenta que diversos fatores explicam a ausência de transferência: o contexto político, a ocorrência de bloqueios e incentivos específicos e a inexistência de crise de superacumulaçáo no período em tela.

Sobre esse último aspecto, Harvey não afirma que a transferência de capital só ocorre no contexto de superacumulação e alguns trabalhos analisam a transferência sem considerar esse aspecto. No entanto, é relevante avaliar a possibilidade desse cenário no Brasil ao longo do período examinado. Ao contrário do que ocorreu na Inglaterra nos anos anteriores ao boom imobiliário do país (início dos anos 2000), a economia brasileira enfrentava em 2007 uma tendência de elevação da lucratividade e de aumento do uso da capacidade instalada da indústria, nível de emprego crescente (Bruno \& Caffe, 2018) e uma elevação relativamente moderada das reservas de caixas das empresas não financeiras. Esses são indícios de que a economia não havia esgotado seu potencial de crescimento. Obviamente a crise de 2008 representou retrocesso nessas variáveis, seguido de posterior retomada, mas os sinais de superaquecimento só surgiriam em 2011-12. Dessa forma, a ausência de crise de superacumulação no período imediatamente anterior ao boom imobiliário ajuda a entender o crescimento concomitante do investimento produtivo e da construçáo de edifícios entre 2007 e 2013.

O contexto político é outra razão pela qual foi possível um nível elevado nos dois tipos de investimento. Em parte do período ainda havia margem para a adoção de políticas desenvolvimentistas, embora cada vez mais contestadas. Essas se manifestaram na sustentação da infraestrutura via investimento e financiamento públicos, com efeitos significativos sobre o investimento privado em máquinas e equipamentos, além de diversas medidas de incentivo ao financiamento e produçáo de moradias, com destaque para o PMCMV, em 2009. O resultado foi o aquecimento substancial do mercado imobiliário nas principais cidades do país. No entanto, a crise neste mercado não ocorreu devido aos mecanismos de contágio e imbricação do "complexo imobiliário-financeiro", como no caso americano, sendo mais uma consequência das próprias crises econômica, política e urbana que caracterizamos como uma "crise administrativa". Cabe especular que a ausência de "estouro" da bolha imobiliária pode ter sido causada também pela fraca transferência de capital entre os circuitos primário e secundário. 
Por outro lado, verifica-se um nítido direcionamento do capital financeiro para o setor imobiliário no período analisado, em diferentes velocidades e fluxos por investidores institucionais e pelo Estado. Isso ocorreu apesar de barreiras ao movimento devido à preferência por renda fixa (mesmo com redução dos juros em parte do período) e a histórica aversão ao risco de investidores institucionais. Portanto, destaca-se a importância de incentivos fiscais a opçóes de investimento (FII, CRI), novas regulaçóes e políticas públicas no amadurecimento do mercado. A existência deste movimento não valida a hipótese da transferência de capital, mas chama atenção para o fato de que a análise da economia política deve privilegiar os incentivos e bloqueios aos fluxos de capital. As transformaçóes no segmento dos investidores institucionais mostram uma certa sensibilidade e rapidez para o investimento e desinvestimento no ambiente construído. O aprimoramento das dimensóes organizacionais do mercado e aprofundamento da financeirização nos setores imobiliário e de infraestrutura tem o potencial de aumentar essa mobilidade.

Por outro lado, o alto peso das famílias e do governo no investimento em construçóes indica que as decisôes privadas empresariais ainda são limitadas no setor, reduzindo o impacto da fluidez de capital, que ainda é muito dependente do Estado. O Estado certamente ocupa papel estrutural de relevo, o que torna necessário o aprofundamento de estudos sobre a politizaçáo das finanças e seu papel no movimento das dívidas (Fraser, 2018), entre famílias, empresas, espaços, níveis de governo e setores da economia.

Por fim, entendemos que o arcabouço da transferência de capital é útil como instrumento de análise para jogar luz em processos de mudanças econômicas e seus efeitos sobre o investimento urbano. Um tema promissor para futuros estudos é aprofundar o entendimento de como os bloqueios e incentivos à mobilidade entre circuitos, bem como os canais de transmissão produtivo-financeiro, foram historicamente configurados numa economia como a brasileira e quais suas reais perspectivas de mudanças diante do aprofundamento da financeirização.

\section{Referências bibliográficas}

Associação Brasileira das Entidades Fechadas de Previdência Complementar (ABrapP). (2019). Estatísticas. http://www.abrapp.org.br/Paginas/estatisticas/estatisticas.aspx

Associação Brasileira das Entidades dos Mercados Financeiros e de Capitais (anbima). (2019). Estatísticas. https://www.anbima.com.br/pt_br/informar/estatisticas/fundos-deinvestimento/fundos-de-investimento.htm

Aveline-Dubach, N. (2020). The financialization of real estate in megacities and its variegated trajectories in East Asia. Em D. Labbé \& A. Sorensen (Eds.), Handbook on Megacities and Megacity-Regions (pp. 394-409). Edward Elgar.

Banco Central do Brasil. (2018). Relatório de Investimento Direto 2018.

Banco Central do Brasil. (2018). Série histórica dos fluxos de investimento direto. https://www. bcb.gov.br/htms/infecon/seriehistfluxoinvdir.asp?frame=1 
Beauregard, R. A. (1994). Capital switching and the built environment: United States, 197089. Environment and Planning A, 26(5), 715-732. https://doi.org/10.1068/a260715

Bruno, M. A. P. \& Caffe, A. R. D. (2018). Determinantes das taxas de lucro e de acumulaçáo no Brasil: os fatores estruturais da deterioração conjuntural de 20142015. Revista de Economia Política, 38(2), 237-260. https://doi.org/10.1590/010131572018v38n02a02

Carvalho, L. (2018). Valsa brasileira. Todavia.

Chistophers, B. (2011). Revisiting the urbanization of capital. Annals of the Association of American Geographers, 101(6), 1347-1364. https://doi.org/10.1080/00045608.2011 .583569

Fainstein, S. (1994). The city builders: Property, politics, and planning in London and New York. Blackwell.

Fix, M. (2011). Financeirização e transformaçóes recentes no circuito imobiliário no Brasil. Tese de Doutorado, Instituto de Economia, Universidade Estadual de Campinas.

Fraser, N. (2018). Crise de legitimação? Sobre as contradiçóes políticas do capitalismo financeirizado. Cadernos de Filosofia Alemã: Crítica E Modernidade, 23(2), 153-188. https://doi.org/10.11606/issn.2318-9800.v23i2p153-188

Gonçalves, R. (2017). Internacionalização das empreiteiras brasileiras, corrupção e vantagem competitiva espúria. Textos para discussão. Instituto de Economia da Universidade Federal do Rio de Janeiro, 11.

Gotham, K. F. (2006). The secondary circuit of capital reconsidered: Globalization and the U.s. real estate sector. American Journal of Sociology, 112(1), 231-275. https://doi. org/10.1086/502695

Halbert, L. \& Rouanet, H. (2014). Filtering risk away: Global finance capital, transcalar territorial networks and the (un)making of city-regions: An analysis of business property development in Bangalore, India. Regional Studies, 48(3), 471-484. https:// doi.org/10.1080/00343404.2013.779658

Harvey, D. (1978). The urban process under capitalism: a framework for analysis. International Journal of Urban \& Regional Research, 2(1), 101-131. https://doi. org/10.1111/j.1468-2427.1978.tb00738.x

Instituto Brasileiro de Geografia e Estatística (IBGE). (2017). Sistema de Contas Nacionais, 2017. https:/www.ibge.gov.br/estatisticas/economicas/industria/9052-sistema-de-contasnacionais-brasil.html? =\&t=resultados

Instituto Brasileiro de Geografia e Estatística (IBGe). (2018). Pesquisa Anual da Indústria da Construção. https://www.ibge.gov.br/estatisticas/economicas/industria/9018-pesquisaanual-da-industria-da-construcao.html $=\& \mathrm{t}=$ resultados

Instituição Fiscal Independente (IFI). (2017). Relatório de Acompanhamento Fiscal, dezembro.

Instituto de Pesquisa Econômica Aplicada (IPEA). (2020). Ipeadata. http://www.ipeadata.gov.br

King, R. (1989). Capital switching and the role of ground rent: 1 Theoretical problems. Environment and Planning A: Economy and Space, 21(4), 445-462. https://doi. org/10.1068/a210445

Klink, J. \& Souza, M. B. (2017). Financeirização: conceitos, experiências e a relevância para o campo do planejamento urbano brasileiro. Cadernos Metrópole, 19(39), 379-406. http://dx.doi.org/10.1590/2236-9996.2017-3902 
Kutz, W. (2016). The Eurozone crisis and emerging-market expansion: capital switching and the uneven geographies of Spanish urbanization. International Journal of Urban and Regional Research, 40(6), 1075-1093. https://doi.org/10.1111/1468-2427.12402

Leitner, H. (1994). Capital markets, the development industry, and urban office market dynamics: rethinking building cycles. Environment and Planning A: Economy and Space, 26(5), 779-802. https://doi.org/10.1068/a260779

Oliveira, G., Cioffi, F. \& Conti, B. (2017). Os Fundos de pensão e o financiamento de longo prazo no Brasil: possibilidades e limites. Revista Pesquisa \& Debate, 28(1), 16-41.

Royal Institution of Chartered Surveyors (RICS). (2014). The Role of international and local valuation standards in influencing valuation practice in emerging and established markets. Report for royal institutions of chartered surveyors. RICs Research.

Rolnik, R. (2015). Guerra dos Lugares: a colonização da terra e da moradia na era das finanças. Boitempo.

Royer, L. (2016). O FGTs e o mercado de títulos de base imobiliária: relaçôes e tendências. Cadernos Metrópole, 18(35), 33-52. https://doi.org/10.1590/2236-9996.2016-3502

Rufino, B. (2016). A incorporação da metropóle: transformaçōes na produção imobiliária e do espaço na fortaleza do século xxi. Annablume.

Sanfelici, D. (2013). Financeirização e a produção do espaço urbano no Brasil: uma contribuição ao debate. Revista EURE - Revista de Estudios Urbano Regionales, 39(118), 27-46. http://dx.doi.org/10.4067/S0250-71612013000300002

Sanfelici, D. \& Halbert, L. (2016). Financial markets, developers and the geographies of housing in Brazil: a supply side account. Urban Studies, 53(7), 1465-1485. https:// doi.org/10.1177/0042098015590981

Santos, C. H. M., Modenesi, A. M., Squeef, G., Vasconcelos, L., Mora, M., Fernandes, T., Moraes, T., Summa, R. \& Braga, J. (2016). Revisitando a dinâmica trimestral do investimento no Brasil: 1996-2012. Revista de Economia Politica, 36(1), 190-213. http://dx.doi.org/10.1590/0101-31572016v36n01a11

SECOVI. (2016). Anuário do Mercado Imobiliário 2016. http://www.secovi.com.br/downloads/ $\mathrm{url} / 2149$

Singer, A. (2015). Cutucando onças com varas curtas: O ensaio desenvolvimentista no primeiro mandato de Dilma Rousseff (2011-2014). Novos Estudos, (102). http://dx.doi. org/10.25091/s0101-3300201500020004

UQBAR. (2017). Anuário uqbar: Securitização e Financiamento Imobiliário. https://www. uqbar.com.br/

Valença, M. (2008). Ensaio sobre a dinâmica do imobiliário em Harvey. Em M. Valença (Org.), Cidade (i)legal (pp. 243-250). Mauad X. 